\title{
Optimal control of a stochastic diffusion process with functional equality and inequality constraints
}

\author{
R.O. Mastaliyev
}

Institute of Control Systems of Azerbaijan National Academy of Sciences, Baku, Azerbaijan

\begin{tabular}{|c|c|}
\hline A R T I CLE I N F O & A B S T R A C T \\
\hline $\begin{array}{l}\text { Article history: } \\
\text { Received 03.09.2021 } \\
\text { Received in revised form } 16.09 .2021 \\
\text { Accepted } 27.09 .2021 \\
\text { Available online } 29.12 .2021 \\
\text { Keywords: } \\
\text { Ito equation } \\
\text { Stochastic control problem with } \\
\text { constraints } \\
\text { Optimal control } \\
\text { Stochastic analogue of the Euler } \\
\text { equation } \\
\text { Analogue of the Legendre-Klebsch } \\
\text { condition }\end{array}$ & $\begin{array}{l}\text { We consider a problem of optimal control of a multidimensional } \\
\text { process specified by Ito stochastic differential equation, in the } \\
\text { presence of functional equality and inequality constraints on the } \\
\text { phase trajectory, with the control acting on the drift coefficient. } \\
\text { Sufficiently general and at the same time constructively verifiable } \\
\text { first- and second-order necessary optimality conditions are } \\
\text { formulated in terms of variations of functionals. }\end{array}$ \\
\hline
\end{tabular}

\section{Introduction}

This article is devoted to the application of the deterministic approach to the optimal control problem for Ito stochastic differential equations in the presence of functional equality and inequality constraints on the trajectory of the system.

Such stochastic optimal control problems without additional functional constraints were studied in [1-3] and others.

It should be noted that similar problems in the deterministic case were investigated in [4-7] and others.

In this article, using a stochastic analogue of the method proposed in [6, 7], under the assumption that the control domain is open, we obtain first- and second-order necessary optimality conditions, including a stochastic analogue of the Euler-Lagrange equation, an analogue of the Legendre-Klebsch condition [8].

The article concludes with a study of special cases (in the classical sense).

\section{Problem statement}

Suppose that $\left(\Omega, \mathcal{F},(\mathcal{F})_{t_{0 \leq t \leq t_{1}}}, P\right)$ is a complete probability space endowed with natural filtration of the $n$-dimensional standard Wiener process $w(t), t \in T=\left[t_{0}, t_{1}\right] . L_{\mathcal{F}}^{2}\left(t_{0}, t_{1} ; R^{n}\right)$ is a

E-mail address: mastaliyevrashad@gmail.com (R.O. Mastaliyev). 
space of processes that are measurable with respect to $(t, \omega)$ and $\mathcal{F}^{t}$-consistent, $x(t, \omega): T \times \Omega \rightarrow R^{n}$, for which

$$
E \int_{t_{0}}^{t_{1}}\|x(t)\|^{2} d t<+\infty
$$

where $E$ is the symbol of mathematical expectation.

Suppose that a controlled process described by Ito stochastic differential equations is specified on this probability space [9]:

$$
d x(t)=f(t, x(t), u(t)) d t+\sigma(t, x(t)) d w(t), t \in T,
$$

with the initial condition

$$
x\left(t_{0}\right)=x_{0} .
$$

Here, $x(t) \in R^{n}$ is the state vector; $f(t, x, u)$ is the specified $n$-dimensional vector function that is continuous in the set of variables together with partial derivatives in $(x, u)$ up to and including the second order; $\sigma(t, x(t)): T \times R^{n} \rightarrow R^{n \times n}$ is a $(n \times n)$-dimensional matrix function that is continuous in the set of variables together with partial derivatives in $x$ up to and including the second order, control $u(t, \omega)$,

$$
u(t, \omega) \in U_{d} \equiv\left\{u(., .) \in L_{\mathcal{F}}^{2}\left(t_{0}, t_{1} ; R^{r}\right) / u(., .) \in U \subset R^{r}, \text { a.s. }\right\},
$$

where $U$ is a specified non-empty, bounded and open set.

The function $u(t) \in U_{d}, t \in T$ will be called an admissible control, if the corresponding solution $x(t)$ of problem (1)-(2) satisfies the constraints

$$
\begin{gathered}
S_{i}(x)=E \varphi_{i}\left(x\left(t_{1}\right)\right) \leq 0, i=\overline{1, p}, \\
S_{i}(x)=E \varphi_{i}\left(x\left(t_{1}\right)\right)=0, i=\overline{p+1, q},
\end{gathered}
$$

where $\varphi_{i}(x), i=\overline{1, q}$ are twice specified continuously differentiable scalar functions.

It is assumed that there is a unique almost sure continuous solution $x(t)$ of system (1)-(2) corresponding to each admissible control $u(t), t \in T$.

Consider the problem of the minimum of the terminal functional

$$
S_{0}(x)=E \varphi_{0}\left(x\left(t_{1}\right)\right),
$$

where $\varphi_{0}(x)$ is twice specified continuously differentiable scalar function.

As noted above, the main aim of this work is to obtain the first- and second-order necessary optimality conditions for considered problem (1)-(6).

\section{Necessary optimality conditions in terms of the first and second variations of the functional}

Assuming that $(u(t), x(t))$ is a fixed admissible process, we introduce the following designations for contracted notation

$$
\begin{gathered}
H\left(t, x, u, \psi_{i}\right)=\psi_{i}{ }^{\prime} f(t, x, u), H_{x}^{(i)}[t]=H_{x}\left(t, x(t), u(t), \psi_{i}(t)\right), H_{u}^{(i)}[t]=H_{u}\left(t, x(t), u(t), \psi_{i}(t)\right), \\
H_{x x}^{(i)}[t]=H_{x x}\left(t, x(t), u(t), \psi_{i}(t)\right), H_{u u}^{(i)}[t]=H_{u u}\left(t, x(t), u(t), \psi_{i}(t)\right), \\
f_{x}[t]=f_{x}(t, x(t), u(t)), f_{u}[t]=f_{u}(t, x(t), u(t)), \\
\sigma_{x}[t]=\sigma_{x}(t, x(t)), \sigma_{x x}[t]=\sigma_{x x}(t, x(t)) .
\end{gathered}
$$

Here, the random processes $\psi_{i}(t) \in L_{\mathcal{F}}^{2}\left(t_{0}, t_{1} ; R^{n}\right)$ and $\beta_{i}(t) \in L_{\mathcal{F}}^{2}\left(t_{0}, t_{1} ; R^{n \times n}\right)$ are the solution to the following system of stochastic differential equations (conjugate system): 


$$
\left\{\begin{array}{c}
d \psi_{i}(t)=-\left(H_{x}^{(i)}[t]+\beta_{i}(t) \sigma_{x}[t]\right) d t+\beta_{i}(t) d w(t), \\
\psi_{i}\left(t_{1}\right)=-\frac{\partial \varphi_{i}\left(x\left(t_{1}\right)\right)}{\partial x} .
\end{array}\right.
$$

Then, using the traditional technique (see, e.g., $[3,8,10]$ ), we will show that the first and second variations (in the classical sense) of the functional $S_{i}$ at the point $u=u(t)$ can be represented as follows:

$$
\begin{gathered}
\delta^{1} S_{i}(u ; \delta u)=-E \int_{t_{0}}^{t_{1}} H_{u}^{(i)^{\prime}}[t] \delta u(t) d t \\
\delta^{2} S_{i}(u ; \delta u)=E\left(\delta x^{\prime}\left(t_{1}\right) \frac{\partial^{2} \varphi_{i}\left(x\left(t_{1}\right)\right)}{\partial x^{2}} \delta x\left(t_{1}\right)-\int_{t_{0}}^{t_{1}} \delta x^{\prime}(t)\left[H_{x x}^{(i)}[t]+\beta_{i}(t) \sigma_{x x}[t]\right] \delta x(t) d t\right. \\
\left.-2 \int_{t_{0}}^{t_{1}} \delta x^{\prime}(t) H_{x u}^{(i)}[t] \delta u(t) d t-\int_{t_{0}}^{t_{1}} \delta u^{\prime}(t) H_{u u}^{(i)}[t] \delta u(t) d t\right), i=\overline{0, q}
\end{gathered}
$$

Here, $\delta u(t) \in L_{\mathcal{F}}^{2}\left(t_{0}, t_{1} ; R^{r}\right)$ is a control variation, an $\delta x(t) \in L_{\mathcal{F}}^{2}\left(t_{0}, t_{1} ; R^{n}\right)$ (trajectory variation) is the solution of the equation in variations:

$$
d \delta x(t)=\left(f_{x}^{\prime}[t] \delta x(t)+f_{u}^{\prime}[t] \delta u(t)\right) d t+\sigma_{x}^{\prime}[t] \delta x(t) d w(t)
$$

with the initial condition

$$
\delta x\left(t_{0}\right)=0 .
$$

Note that, in accordance with [11], the solution to problem (9)-(10) allows the representation

$$
\delta x(t)=\int_{t_{0}}^{t} R(t, \tau) \delta u(\tau) d \tau,
$$

where by definition

$$
R(t, \tau)=Q(t, \tau) f_{u}[\tau]
$$
equation:

Here the fundamental matrix $Q(t, \tau)-(n \times n)$ is a solution to the homogeneous stochastic

$$
\begin{gathered}
d Q(t, \tau)=f_{x}^{\prime}[t] Q(t, \tau) d t+\sigma_{x}^{\prime}[t] Q(t, \tau) d w(t), \\
Q(t, t)=I(I-\text { identity matrix }) .
\end{gathered}
$$

Using the proof scheme from [5-7], we can prove

Theorem 1. (first-order necessary optimality condition). It is necessary for the optimality of the admissible pair $(u(t), x(t))$ that a nonzero set of Lagrange multipliers $\lambda=\left(\lambda_{0}, \lambda_{1}, \ldots, \lambda_{q}\right) \in R^{q+1}$ exist in stochastic problem (1)-(6), such that

$$
\begin{aligned}
\lambda_{i} \geq 0, i & =\overline{0, p}, \\
\lambda_{i} E \varphi_{i}\left(x\left(t_{1}\right)\right) & =0, i=\overline{1, p},
\end{aligned}
$$

and that the following equality hold for all $\delta u(t) \in L_{\mathcal{F}}^{2}\left(t_{0}, t_{1} ; R^{r}\right)$ :

$$
E \sum_{i=0}^{q} \lambda_{i} \delta^{1} S_{i}(u ; \delta u)=0 .
$$

Substituting into (12) value (7) of the first variation of the functional $\delta^{1} S_{i}(u ; \delta u)$ and applying 
the main lemma (see, e.g., [12]) of the calculus of variations, we have the validity of

Theorem 2. Let there exist a non-zero set of Lagrange multipliers $\lambda=\left(\lambda_{0}, \lambda_{1}, \ldots, \lambda_{q}\right) \in R^{q+1}$, such that the conditions of Theorem 1 are satisfied. Then it is necessary for the optimality of the admissible pair $(u(t), x(t))$ that the following equality hold in stochastic problem (1)-(6):

$$
E \sum_{i=0}^{q} \lambda_{i} H_{u}^{(i)}[\theta]=0
$$

for almost all arbitrary Lebesgue points of the control $u(t), \theta \in\left[t_{0}, t_{1}\right)$.

As we can see, the last equality is a stochastic analogue of the Euler-Lagrange equation for considered problem (1)-(6).

Let us denote by $A(u)$ the set of all Lagrange vectors $\lambda \in R^{q+1}$ of problem (1)-(6) that satisfy the conditions of Theorem 1.

Following the works [4-7], we introduce the set of critical variations $\delta u(t) \in L_{\mathcal{F}}^{2}\left(t_{0}, t_{1} ; R^{r}\right)$ of the control $u(t), t \in T$ and denote by $K(u ; \delta u)$ :

$$
K(u ; \delta u)=\left\{\delta u(t) \in L_{\mathcal{F}}^{2}\left(t_{0}, t_{1} ; R^{r}\right), \delta^{1} S_{i}(u ; \delta u) \leq 0, i=\overline{0, p}, \delta^{1} S_{i}(u ; \delta u)=0, i=\overline{p+1, q}\right\} .
$$

From the results obtained in [4-7] in relation to problem (1)-(6), we obtain that it is necessary for the optimality of the admissible pair $(u(t), x(t))$ that the following inequality hold for all $\delta u(t) \in$ $K(u ; \delta u)$ :

$$
\max _{\lambda \in A(u)} E \sum_{i=0}^{q} \lambda_{i} \delta^{2} S_{i}(u ; \delta u) \geq 0
$$

Let us proceed to the derivation of other second-order necessary optimality conditions. For this purpose, we will use second-order implicit necessary optimality condition (13).

Using representation (11), following, for instance, [3, 7, 10], we can obtain the following identities

$$
\begin{gathered}
\delta x^{\prime}\left(t_{1}\right) \frac{\partial^{2} \varphi_{i}\left(x\left(t_{1}\right)\right)}{\partial x^{2}} \delta x\left(t_{1}\right)= \\
=\int_{t_{0}}^{t_{1}} \int_{t_{0}}^{t_{1}} \delta u^{\prime}(\tau) R\left(t_{1}, \tau\right) \frac{\partial^{2} \varphi_{i}\left(x\left(t_{1}\right)\right)}{\partial x^{2}} R\left(t_{1}, s\right) \delta u(s) d \tau d s, \\
\int_{t_{0}}^{t_{1}} \delta x^{\prime}(t)\left[H_{x x}^{(i)}[t]+\beta_{i}(t) \sigma_{x x}[t]\right] \delta x(t) d t= \\
=\int_{t_{0}}^{t_{1}} \int_{t_{0}}^{t_{1}} \delta u^{\prime}(\tau)\left[\int_{\max (\tau, s)}^{t_{1}} R(t, \tau)\left[H_{x x}^{(i)}[t]+\beta_{i}(t) \sigma_{x x}[t]\right] R(t, s) d t\right] \delta u(s) d s d \tau, \\
\int_{t_{0}}^{t_{1}} \delta x^{\prime}(t) H_{x u}^{(i)}[t] \delta u(t) d t=\int_{t_{0}}^{t_{1}}\left[\int_{t}^{t_{1}} \delta u^{\prime}(\tau) H_{x u}^{(i)}[\tau] R(t, \tau) d \tau\right] \delta u(t) d t .
\end{gathered}
$$

In addition, by analogy with $[3,7,10]$, we suppose that

$$
K^{(i)}(\tau, s)=-R\left(t_{1}, \tau\right) \frac{\partial^{2} \varphi_{i}\left(x\left(t_{1}\right)\right)}{\partial x^{2}} R\left(t_{1}, s\right)+\int_{\max (\tau, s)}^{t_{1}} R(t, \tau)\left[H_{x x}^{(i)}[t]+\beta_{i}(t) \sigma_{x x}[t]\right] R(t, s) d t .
$$

Hence, using identities (14)-(16) and taking into account the last notation, we can transform second variation (8) of the functional $S_{i}(u)$ to the form 


$$
\begin{aligned}
\delta^{2} S_{i}(u ; \delta u)= & -E\left\{\int_{t_{0}}^{t_{1}} \int_{t_{0}}^{t_{1}} \delta u^{\prime}(\tau) K^{(i)}(\tau, s) \delta u(s) d \tau d s+\int_{t_{0}}^{t_{1}} \delta u^{\prime}(t) H_{u u}^{(i)}[t] \delta u(t) d t+\right. \\
& \left.+2 \int_{t_{0}}^{t_{1}}\left[\int_{t}^{t_{1}} \delta u^{\prime}(\tau) H_{x u}^{(i)}[\tau] R(\tau, t) d \tau\right] \delta u(t) d t\right\} .
\end{aligned}
$$

Comparing expressions (13) and (17), it is easy to see the validity of

Theorem 3. It is necessary for the optimality of the admissible pair $(u(t), x(t))$ in stochastic problem (1)-(6) that the following inequality hold for all $\delta u(t) \in K(u ; \delta u)$ :

$$
\begin{gathered}
\min _{\lambda \in A(u)} E\left\{\int_{t_{0}}^{t_{1}} \int_{t_{0}}^{t_{1}} \delta u^{\prime}(\tau) K^{(\lambda)}(\tau, s) \delta u(s) d \tau d s+\int_{t_{0}}^{t_{1}} \delta u^{\prime}(t) H_{u u}^{(\lambda)}[t] \delta u(t) d t+\right. \\
\left.+2 \int_{t_{0}}^{t_{1}}\left[\int_{t}^{t_{1}} \delta u^{\prime}(\tau) H_{x u}^{(\lambda)}[\tau] R(\tau, t) d \tau\right] \delta u(t) d t\right\} \leq 0 .
\end{gathered}
$$

Here, by definition

$$
K^{(\lambda)}(\tau, s)=\sum_{i=0}^{q} \lambda_{i} K^{(i)}(\tau, s), H_{u x}^{(\lambda)}[t]=\sum_{i=0}^{q} \lambda_{i} H_{u x}^{(i)}[t], H_{u u}^{(\lambda)}[t]=\sum_{i=0}^{q} \lambda_{i} H_{u u}^{(i)}[t] .
$$

Note that inequality (18) is itself a source of obtaining optimality conditions. Here are some of them.

Assuming in (18)

$$
\delta u_{\varepsilon}(t)=\left\{\begin{array}{r}
u, t \in[\theta, \theta+\varepsilon), \\
0, t \notin[\theta, \theta+\varepsilon)
\end{array}\right.
$$

where $\varepsilon>0$ is a sufficiently small arbitrary number such that $\theta+\varepsilon<t_{1}, \theta \in\left[t_{0}, t_{1}\right)$ is a arbitrary Lebesgue point of the control $u(t), u \in R^{r}$ is an arbitrary vector, we arrive at

Corollary (stochastic analogue of the Legendre-Klebsch condition). Along the optimal process $(u(t), x(t))$ for all $u \in R^{r}$ and $\theta \in\left[t_{0}, t_{1}\right)$

$$
\min _{\lambda \in A(u)} E u^{\prime} H_{u u}^{(\lambda)} u \leq 0 .
$$

Now we consider the case of degeneration of the Legendre-Klebsch condition.

Definition $[6,8]$. The admissible control $u(t)$ will be called singular in the classical sense in stochastic problem (1)-(6), if for all $u \in R^{r}, \theta \in\left[t_{0}, t_{1}\right)$

$$
\min _{\lambda \in A(u)} E u^{\prime} H_{u u}^{(\lambda)} u=0 \text {. }
$$

Now, assuming in (18)

$$
\delta u(t)=\left\{\begin{array}{l}
0, t \in\left[t_{0}, \theta\right) \\
u, t \in\left[\theta, t_{1}\right)
\end{array}\right.
$$

then according to the scheme of [6] we obtain

Theorem 4. It is necessary for the optimality of the singular, in the classical sense, pair $(u(t), x(t))$ in stochastic problem (1)-(6) that for all $u \in R^{r}$ and $\theta \in\left[t_{0}, t_{1}\right)$ that satisfy the conditions

$$
H_{u}^{(i)^{\prime}}[\theta] u \geq 0, i=\overline{0, p}, H_{u}^{(i)^{\prime}}[\theta] u=0, i=\overline{p+1, q}
$$


the following relations hold:

$$
\min _{\lambda \in A(u)} E u^{\prime}\left(K^{(\lambda)}(\theta, \theta)+H_{x u}^{(\lambda)}[\theta] f_{u}[\theta]\right) u \leq 0 .
$$

\section{Conclusion}

We have found first- and second-order necessary optimality conditions in terms of variations of functionals in a stochastic control problem in the presence of functional equality and inequality constraints at the end of the system trajectory.

\section{References}

[1] К.А. Рыбаков, И.Л. Сотскова, Оптимальное управление нелинейными системами со случайной структурой при непольной информации о векторе состояния, Автомат. и телемех., №7 (2006) с. 62-75. [In Russian: K.A. Rybakov, I.L. Sotskova, Optimal control of nonlinear systems with a random structure with incomplete information about the state vector, Avtomatika i telemekhanika].

[2] H. Zhang, X. Zhang. Second-order necessary conditions for stochastic optimal control problems, SIAM Rev. 60(2018) pp. 139-178.

[3] R.O. Mastaliyev, First and second order necessary optimality conditions in control problems described by stochastic differential equations, Informatics and Control Problems. 41 No.1 (2021) pp.19-27.

[4] Н.П. Осмоловский, Условия второго порядка слабого локального минимума в задаче оптимального управления (необходимость, достаточность), Докл. АН СССР. 225 No.2 (1975) с.259-262. [In Russian: N.P. Osmolovskiy, Second-order conditions for a weak local minimum in an optimal control problem (necessity, sufficiency), Dokl. AN SSSR].

[5] В.В. Гороховик, Необходимые условия слабой эффективности в задаче управления с векторным показателем качества, Минск, (1976) 44 р. (Препринт, Институт математики АН БССР: No.13 (13)). [In Russian: V.V. Gorokhovik, Necessary conditions of weak efficiency in a control problem with a vector quality indicator, Minsk].

[6] А.И. Калинин, К проблеме особых оптимальных управлений, Диф. урав. 21 No.3 (1985) c.380-385. [In Russian: A.I. Kalinin, On a problem of singular optimal controls, Dif. urav.].

[7] А.А. Абдуллаев, К.Б. Мансимов, Необходимые условия оптимальности в процессах, описываемых системой интегральных уравнений типа Вольтерра, Баку, ЭЛМ, (2013) 224 c. [In Russian: A.A. Abdullayev, K.B. Mansimov, Necessary optimality conditions in processes described by a system of Volterra integral equations, Baku, ELM].

[8] Р. Габасов, Ф.М. Кириллова, Особые оптимальные управления, Москва, Книжный дом «Либроком», (2013) 256 c. [In Russian: R. Gabasov, F.M. Kirillova, Singular optimal controls, Moscow, Librokom].

[9] А.А. Леваков, Стохастические дифференциальные уравнения, Минск, БГУ, (2009) 231c. [In Russian: A.A. Levakov, Stochastic differential equations, Minsk, BSU].

[10] Р.О. Масталиев, Необходимые условия оптимальности второго порядка в одной стохастической задаче оптимального управления с переменным запаздывающим аргументом, Вестн.Сам.гос.техн.ун-та, Сер. физ.-мат. наук. 20 No.4 (2016) c.620-635. [In Russian: R.O. Mastaliyev, Second-order necessary optimality conditions in a stochastic optimal control problem with a variable retarded argument, Vestnik Sam.Gos.Techn.Un.-ta.Ser.Fiz.-Mat.Nauk].

[11] Ю.М. Кабанов, О принципе максимума Понтрягина для линейных стохастических дифференциальных уравнений, В сб. «Вероятностные модели и управление экономическими процессами», Москва, ЦЭМИ АН CCCP. (1978) c.85-94. [In Russian: Yu.M. Kabanov, On the Pontryagin maximum principle for linear stochastic differential equations, in Col. "Probabilistic models and management of economic processes", M., TSEMI AN SSSR].

[12] В.М. Алексеев, В.М. Тихомиров, С.В. Фомин, Оптимальное управление, Москва, Наука, (1979) 432c. [In Russian: V.M. Alekseyev, V.M. Tikhomirov, S.V. Fomin, Optimal control, Moscow, Nauka]. 